\title{
Network Effects of the Productivity of Infrastructure in Developing Countries*
}

\author{
Christophe Hurlin **
}

\begin{abstract}
Using panel data models we examine the threshold effects of the productivity of infrastructure investment in developing countries. We consider various specifications of an augmented production function that allow for endogenous thresholds. More precisely, these specifications are tested in a panel threshold regression. Our main robust result is the presence of strong threshold effects in the relationship between output and private and public inputs. Whatever the transition mechanism used, the testing procedures lead to strong rejection of the linearity of this relationship. In particular, the productivity of infrastructure investment generally exhibits some network effects. When the available stock of infrastructure is very low, investment in this sector has the same productivity as non-infrastructure investment. On the contrary, when a minimum network is available, the marginal productivity of infrastructure investment is generally largely greater than the productivity of other investments. Finally, when the main network is achieved, its marginal productivity becomes similar to the productivity of other investment.
\end{abstract}

Keywords : Infrastructure, Threshold Panel Regression Models.

J.E.L Classi.cation : C82, E22, E62.

World Bank Policy Research Working Paper 3808, January 2006

The Policy Research Working Paper Series disseminates the findings of work in progress to encourage the exchange of ideas about development issues. An objective of the series is to get the findings out quickly, even if the presentations are less than fully polished. The papers carry the names of the authors and should be cited accordingly. The findings, interpretations, and conclusions expressed in this paper are entirely those of the authors. They do not necessarily represent the view of the World Bank, its Executive Directors, or the countries they represent. Policy Research Working Papers are available online at http://econ.worldbank.org.

* would like to thank Santiago Herrera for his support and his comments on a previous version of this work. I also thank Mohamed Belkir for his comments.

**EO, University of Orléans. Rue de Blois. BP 6739. 45067 Orléans Cedex 2. France. Email address:

christophe.hurlin@univ-orleans.fr. 


\section{Introduction}

Most of the public investments, and particularly public investments in infrastructure, are generally devoted to the construction of networks. It is particularly clear when we consider public investments in roads, railways, telecommunications, electricity, water and sewer systems, but it is also true when we consider some residential public investments devoted for instance to educational buildings. In this case, as noted by Romp and De Haan (2005), the internal composition of the stock matters, since the marginal productivity of one link depends on the capacity and configuration of all the links in the network. Using measures of the total stock, hence, may allow estimation of the average marginal product of roads in the past. However these estimates may not be appropriate for evaluating the marginal product of additional roads today. This argument was in particular used by Fernald (1999) to asses the link between public capital and productivity in the road sector in the United States. To quote the title of his paper, his evaluation based on industry data does not support the idea that public investment offers a continuing and neglected route to prosperity. More precisely, his estimations do not allow rejecting the hypothesis that roads now offer a normal (or even zero) rate of return. He concludes that "the data seem consistent with a story in which the massive road-building of the 1950's and 1960's offered a one-time boost to the level of productivity, rather than a path to continuing rapid growth in productivity. This conclusion - that roads were exceptionally productive before 1973 but not exceptionally productive at the margin - is consistent with simple network argument. In particular, building an interstate network might be very productive; building a second network may not" (Fernald, 1999, page 621). This network character is likely to be generalized to the main components of public investments not only in the United States, but also in most of developing countries.

What is the main implication of this network dimension for the evaluation of the productivity of infrastructure? It clearly implies that the relationship between the output and the level of public capital stock (or infrastructure stocks) is strongly non linear. More precisely, this relationship may depend on the level of infrastructure actually available and may be represented as a threshold model. For instance, let us admit, as Fernald (1999) does, that the construction of the network boosts substantially the total factor productivity and the output, but when the construction of the network is completed, the infrastructure investments may be not exceptionally productive at the margin. Thus, the marginal productivity of these investments is not identical given the level of stock actually available in the country: a low level of infrastructure stock (relatively to the population or to the workforce for instance) indicates that the construction of the network is not completed and implies a high productivity, and a high level of stocks implies, if the network is built, a null or low marginal productivity. These properties clearly correspond to the definition of a threshold regression model: "threshold regression models specify that individual observations can be divided into classes based on the value of an observed variable" (Hansen, 1999, page 346). 
In this paper, we propose to use these threshold regression models in order to take into account this original dimension in the estimation of the rates of return on public capital stocks, i.e. the potential presence of threshold effects. Applying the so-called production function approach introduced by Aschauer (1989), we consider various specifications of public capital stock augmented production functions. At this stage, a remark has to be made. So far, we indifferently used the terms of public capital and infrastructure. However, the notion of infrastructure does not fully correspond to the concept of public sector investment expenditure. This distinction is particularly important when it comes to interpret the threshold effects. Indeed, it would be naïve to directly interpret the threshold effects in the productivity of public capital as network effects: the public investments are so heterogeneous, that the level of public investments or the public capital stocks can not be used to reveal information on the completion of the main infrastructure networks. For this reason, in this paper, we only consider the threshold effects of the productivity of the infrastructure investments.

More precisely, we propose to re-evaluate the marginal productivity of infrastructure stocks using threshold regression models, in which the threshold variable may be defined as the level of the infrastructure stock actually available. The main concern with these models is that they require an important number of observations to be estimated since they depend on an important number of parameters. This concern is particularly relevant in our context, since the time dimension of the series of infrastructure stocks is generally not sufficient to estimate such models, even if we consider only two regimes ${ }^{1}$. One solution is to use panel data as it is generally done in the literature devoted to linear representations of the productivity of infrastructure. In a seminal paper, Hansen (1999) proposed the first procedure to estimate and to test the threshold effects in nondynamic panels. His Panel Threshold Regression (PTR) model allows for dividing the individual observations into classes according to an observable variable. In this case, the time series and cross sections are used in order to identify the regimes. Based on his procedure, it is then possible to test and to estimate the threshold effects in the marginal productivity of infrastructures in a panel of countries, without assuming the homogeneity of the aggregated production function. This model assumes a transition from one regime to another based on the value of a threshold variable, the infrastructure stock for instance: in a model with two regimes, if the threshold variable is below a certain value, called the threshold parameter, the productivity is defined by one model, and it is defined by another model if the threshold variable exceeds the threshold parameter.

It is important to note that the existence of threshold effects in the productivity of infrastructure is compatible with the three major criticisms addressed to the linear specifications of the production function in the huge literature devoted to this topic (see Gramlich, 1994; Sturm, 1998 or Romp and De Haan, 2005 for a survey). Indeed, when it comes to estimate the rates of return on infrastructure (or public capital) with an augmented production function in a panel, three major problems are generally raised. The first one is the potential reverse causation. If public investments depend on income,

\footnotetext{
${ }^{1}$ This is the main reason why these models have not been used even in the case of OECD countries. To the best of our knowledge no study devoted to the productivity of public capital and based on threshold models has yet been proposed.
} 
it implies a feedback from income to the capital stocks. Consequently, the linear regression of the output on the public and private factors does not allow to directly identify the parameters of the production function. Several solutions have been proposed in the literature in order to take into account this problem of reverse causation. Canning (1999) and Canning and Bennathan (2000) argue that the use of panel estimates under various assumptions allows to identify the long run production function relationship. Another solution consists in estimating a system of simultaneous equations: one equation for the production function and another equation for the relationship between the public capital stock and the production (Demetriades and Mamuneas, 2000). Finally, the reverse causation problem can be tackled with an instrumental variable approach or a generalized method of moments. It is for instance the case in Finn (1993), HoltzEakin (1994), Baltagi and Pinnoi (1995), Ai and Cassou (1995), Otto and Voss (1998) and more recently in Calderon and Serven (2004). But the reverse causation issue can also be interpreted as the consequence of threshold effects. For instance, let us assume that the true data generating process of the marginal productivity is a threshold model as suggested by Fernald (1999). The infrastructure investments enhance the output until the completion of the main networks, and once they are finished it is mainly the output which causes the changes in the infrastructure capital stocks. In this case, the use of a linear specification leads to an estimated correlation which takes into account both the influence of the infrastructures on the output in the first period and the influence of the output on the infrastructure stock in the second period. On the contrary, the use of a threshold model based on the value of the capital stock per capita for instance, makes it possible to identify the influence of the infrastructures on the total factor productivity in the first period.

The second major problem raised in the literature is the non stationarity and the non cointegration of the data used in the augmented production function (Tatom, 1991; Sturm and Haan, 1995; Crowder and Himarios, 1997). In time series, it is generally recognized that unit root tests based on linear specifications (ADF, KPSS etc.) are likely to conclude to the non stationarity of series when the true data generating model is a threshold model (SETAR, STAR etc.). Even if similar studies have not been done with panel unit root tests, it is obvious that the first generation tests, as the Im, Pesaran and Shin's test (2003) based on an average of individual ADF statistics, are likely to yield the same kind of results.

The last major problem, which is specific to the panel estimates, is the potential heterogeneity of the parameters of the production function and more particularly the heterogeneity of the elasticities of output with respect to infrastructure (or public capital) stocks. It is common, both in cross section and in panel data studies, to assume that the parameters are common across countries. However, this assumption may raise important problems when the countries of the panel are very different, as it is the case in our sample of developing countries. Consequently, the studies based on a production approach are generally based on specifications with fixed or random individual effects (Evans and Karras, 1994; Holtz-Eakin; 1994). But, to the best of our knowledge, few studies in the literature allow the other parameter of the augmented production function 
to vary across countries ${ }^{2}$. Canning (1999) or Canning and Bennathan (2000) investigate the possible heterogeneity of the production function by splitting their sample into two groups of countries based on their levels of income per worker in a baseline year. Their results based on a Cobb-Douglas production function show that the coefficients on the infrastructure terms in poorer countries are very small, and statistically insignificant, but they remain large, and significant, in richer countries. They conclude that "infrastructure in the poorer countries appears to have the same effectiveness in raising output as other types of physical capital while having a greater effectiveness than other types of capital in richer countries" (Canning and Bennathan, 2000, page 13). In this case, the cross-country heterogeneity of the production technology can be interpreted as the consequence of threshold effects. The idea is very simple: at each date in the threshold model, the countries are divided into a small number of classes with the same elasticities according to an observable variable. This threshold variable can be defined for instance as the level of income per capita according to the decomposition used by Canning and Bennathan (2000). But, the main difference is that the heterogeneity of the production technology is then endogenously determined by the threshold model and not specified ex-ante by splitting the sample into two or three groups of countries. To sum it up, the existence of a nonlinearity and more specifically of threshold effects in the productivity of public capital and infrastructure stocks is largely compatible with the main empirical observations done in the literature.

The paper is organized as follows. In a second section, we explore the threshold effects in the productivity of infrastructures in road, electricity, telephone and railways sectors. For that we consider various panel threshold specifications of an infrastructure augmented production function. In a third section the data are presented and we report the results obtained in linear specifications in order to get a benchmark. In sections four and five, we test the hypothesis of network effects and the influence of the income heterogeneity on the production technology. A last section concludes.

\section{The Productivity of Infrastructure: Toward a Thresh- old Specification}

The basis of our empirical approach is exactly the same as that used by many authors since the seminal paper of Aschauer (1989), and more recently by Canning (1999), Canning and Bennathan (2000) or Calderon and Serven (2004) for developing countries. It consists in estimating the parameters of an infrastructure augmented production function. We follow the literature in adopting a Cobb-Douglas specification of the production function. If we consider a country $i=1, . ., N$ at a time $t=1, ., T$, we assume that:

$$
Y_{i t}=A_{i} K_{i t}^{\alpha} H_{i t}^{\beta} X_{i t}^{\gamma} L_{i t}^{1-\alpha-\beta-\gamma} V_{i t}
$$

where $Y_{i t}$ is the aggregate added value, $K_{i t}$ is the physical capital, $H_{i t}$ is human capital, $X_{i t}$ is infrastructure and $V_{i t}$ is an error term. As usual in this kind of literature, we

\footnotetext{
${ }^{2}$ With random coefficient models for instance (Swamy, 1970).
} 
assume that the infrastructure services are proportional to the infrastructure capital stock. Moreover, we assume constant returns to scale, so that the sum of exponents is one. Dividing through by $L_{i t}$ and taking logs, we have the following expression:

$$
y_{i t}=a_{i}+\alpha k_{i t}+\beta h_{i t}+\gamma x_{i t}+v_{i t}
$$

where $v_{i t}=\log \left(V_{i t}\right)$ and capital stocks and output are in log per worker terms. The individual fixed effects $a_{i}$ capture all the timeless components of the total factor productivity. It is also possible to include in this linear specification, some time effects to capture the common factors in the total factor productivity. The equation (2) correspond exactly to the model estimated by Canning (1999), Canning and Bennathan (2000) or Calderon and Serven (2004). As noted by these authors it is difficult to interpret directly the parameters of equation (2), since infrastructure capital appears twice, once its own but also as a part of aggregate capital $K_{i t}$. Consequently, the parameter $\gamma$ cannot be interpreted as the infrastructure elasticity. More precisely, Canning (1999) shows "that in this case the parameter $\gamma$ captures the extent to which the productivity of infrastructure exceeds (if $\gamma>0$ ) or falls short (if $\gamma<0$ ) the productivity of non infrastructure capital" (Calderon and Serven, 2004, page 98). Thus, the elasticity of output with respect to infrastructure is not constant and depends on the ratio of capital stocks. However, as noted by Calderon and Serven (2004), because infrastructure stocks typically account for relatively small portions of overall capital stock, the difference between the genuine elasticity evaluated around the sample mean and the naïve estimate $\gamma$ should be fairly modest in practice.

As it was previously mentioned, in this study we propose to consider exactly the same framework as that studied in this literature, except the fact that we introduce a non-linearity in order to test and to match the network dimension of infrastructure. In order to take into account this specificity of infrastructure, a solution consists in adopting a Panel Threshold Regression (PTR) model similar to that proposed by Hansen (1999):

$$
y_{i t}= \begin{cases}a_{i}+\alpha_{1} k_{i t}+\beta_{1} h_{i t}+\gamma_{1} x_{i t}+\varepsilon_{i t} & \text { if } q_{i t} \leq \lambda \\ a_{i}+\alpha_{2} k_{i t}+\beta_{2} h_{i t}+\gamma_{2} x_{i t}+\varepsilon_{i t} & \text { if } q_{i t}>\lambda\end{cases}
$$

where $q_{i t}$ denotes a threshold variable and $\lambda$ denotes a threshold parameter. This model can be rewritten as:

$$
y_{i t}=a_{i}+\delta_{1}^{\prime} W_{i t} \mathbb{I}_{\left(q_{i t} \leq \lambda\right)}+\delta_{2}^{\prime} W_{i t} \mathbb{I}_{\left(q_{i t}>\lambda\right)}+\varepsilon_{i t}
$$

where $\delta_{j}=\left(\alpha_{j} \beta_{j} \gamma_{j}\right)^{\prime}$ for $j=1,2$ and $W_{i t}=\left(k_{i t} h_{i t} x_{i t}\right)^{\prime}$, and where $\mathbb{I}_{(.)}$is the indicator function. The error $\varepsilon_{i t}$ is assumed to be independent and identically distributed with mean zero and finite variance $\sigma^{2}$. Two remarks must be made here. In this model the observations are divided into two regimes depending on whether the threshold variable $q_{i t}$ is smaller or larger than the threshold parameter $\lambda$. No constraint is imposed on the choice of the threshold variable except the fact that it cannot be the contemporaneous endogenous variable and it cannot be time independent. We will discuss further the choice of this threshold variable. The second remark is that in Hansen (1999) the individual effects $a_{i}$ are not different in the two regimes. It would be possible to consider 
a constant or $N$ individual constant specific to each regime but it would largely increase the number of parameters of the model. Thus, the regimes are distinguished by differing elasticities $\delta_{1}$ and $\delta_{2}$. The elasticities of output with respect to the three inputs (total capital, infrastructure and human capital) are assumed to be regime dependent.

Naturally, a general specification can be studied with more than two regimes. The procedure of estimation proposed by Hansen allows considering a model with $K$ regimes, however in this study we limit our investigation to models with at the most four regimes (three threshold parameters). For example, threshold models with respectively three and four regimes (respectively two and three threshold parameters) take the form:

$$
\begin{gathered}
y_{i t}=a_{i}+\delta_{1}^{\prime} W_{i t} \mathbb{I}_{\left(q_{i t} \leq \lambda_{1}\right)}+\delta_{2}^{\prime} W_{i t} \mathbb{I}_{\left(\lambda_{1}<q_{i t} \leq \lambda_{2}\right)}+\delta_{3}^{\prime} W_{i t} \mathbb{I}_{\left(q_{i t}>\lambda_{2}\right)}+\varepsilon_{i t} \\
y_{i t}=\begin{array}{l}
a_{i}+\delta_{1}^{\prime} W_{i t} \mathbb{I}_{\left(q_{i t} \leq \lambda_{1}\right)}+\delta_{2}^{\prime} W_{i t} \mathbb{I}_{\left(\lambda_{1}<q_{i t} \leq \lambda_{2}\right)} \\
+\delta_{3}^{\prime} W_{i t} \mathbb{I}_{\left(\lambda_{2}<q_{i t} \leq \lambda_{3}\right)}+\delta_{4}^{\prime} W_{i t} \mathbb{I}_{\left(q_{i t}>\lambda_{3}\right)}+\varepsilon_{i t}
\end{array}
\end{gathered}
$$

where the threshold parameters $\lambda_{j}$ are sorted, $\lambda_{1}<. .<\lambda_{K}$. In all the cases, the parameters $\delta_{j}, j=1,, . . K$ are estimated according to the same simple least square sequential procedure as that used for the standard STAR or SETAR models for times series. If we consider the single threshold model (equation 4 ), for a given value of the threshold parameter $\lambda$, the slope coefficients $\delta_{1}$ and $\delta_{2}$ can be estimated by OLS. Let us denote $\widehat{\delta}_{1}(\lambda)$ and $\widehat{\delta}_{2}(\lambda)$, the corresponding estimates. Thus, conditionally to a value of $\lambda$ it is possible to compute the sum of squared errors, denoted $S_{1}(\lambda)$.

$$
S_{1}(\lambda)=\sum_{i=1}^{N} \sum_{t=1}^{T} \widehat{\varepsilon}_{i t}^{2}(\lambda)
$$

The threshold parameter $\lambda$ is then estimated by minimizing the sum of squared $S_{1}(\lambda)$.

$$
\widehat{\lambda}=\underset{\lambda \in \Lambda}{\operatorname{ArgMin}} S_{1}(\lambda)
$$

Since this sum of squared residuals depends on $\lambda$ only through the indicator function, it is a step function with at most $N T$ steps, with the steps occurring at distinct values of $q_{i t}$ in the sample. Thus, the minimization problem can be reduced to searching over values of $\lambda$ equalling at the most distinct values of $q_{i t}$ in the sample. Given the value of the estimate $\widehat{\lambda}$, it is then possible to get the estimates of the elasticities in the regimes, i.e. $\widehat{\delta}_{1}(\hat{\lambda})$ and $\widehat{\delta}_{2}(\widehat{\lambda})$, and the estimates of individual effects $\widehat{a}_{i \text {. As }}$ it was stressed by Hansen (1999), it is undesirable for a threshold $\widehat{\lambda}$ to be selected which sorts too few observations into one or other regime. That is why we consider an optimization domain $\Lambda$ which assures that a minimal percentage of the observations lie in each regime. More precisely, the minimization program (8) can be solved by a direct search over the values of $\gamma$ equalling the at most $N T$ distinct values of the threshold variable $q_{i t}$ in the sample. If we sort the $N T$ distinct values of the observations on $q_{i t}$, the previous constraint implies to eliminate the smallest and largest values. The remaining values constitutes the set $\Lambda$ of values of $\lambda$ which can be searched for $\widehat{\lambda}$. In our 
application, smallest and largest $5 \%$ values are eliminated. The same kind of procedure is used for models with three or four regimes. Thus, for each model, at least $5 \%$ of the total of the NT observations is available to estimate the elasticities in each regime.

In this threshold model, there are two main problems. The first one consists of testing the number of regimes or equivalently in testing the threshold specification. The second issue consists of choosing the threshold variable. Let us assume that the threshold variable is known. If one comes to test whether the threshold effect is statically significant in the model with two regimes (equation 4), the null hypothesis is $H_{0}: \delta_{1}=\delta_{2}$. This null hypothesis corresponds to the hypothesis of no threshold effect. Under $H_{0}$ the model is then equivalent to a linear model (equation 2). This hypothesis could be tested by a standard test. If we note $S_{0}$ the sum of squared of the linear model, the approximate likelihood ratio test of $H_{0}$ is based on:

$$
F_{1}=\frac{S_{0}-S_{1}(\widehat{\lambda})}{\widehat{\sigma}^{2}}
$$

where $\widehat{\sigma}^{2}$ denotes a convergent estimate of $\sigma^{2}$. The main problem is that under the null the threshold parameter $\lambda$ is not identified. Consequently, the asymptotic distribution of $F_{1}$ is not standard and in particular does not correspond to a chi-squared distribution. This issue has been largely studied in the literature devoted to the threshold models, notably since the seminal paper of Hansen (1996). One solution consists in simulating by Bootstrap the asymptotic distribution of the statistic $F_{1}$. Hansen (1996) shows that a bootstrap procedure attains the asymptotic distribution, so p-values constructed from the bootstrap are asymptotically valid. As proposed by Hansen (1999) in the context of panel models, we use bootstrap simulations ${ }^{3}$ to compute the critical values of the distribution of the statistics of tests on the number of thresholds.

The same kind of procedure can be applied in general models (equations 5 or 6 ) in order to determining the number of thresholds. If the p-value associated to $F_{1}$ leads to rejects the linear hypothesis, we then discriminate between one and two thresholds. A likelihood ratio test of one threshold versus two thresholds is based on the statistic

$$
F_{2}=\frac{S_{1}(\widehat{\lambda})-S_{2}\left(\widehat{\lambda}_{1}, \widehat{\lambda}_{2}\right)}{\widehat{\sigma}^{2}}
$$

where $\widehat{\lambda}_{1}$ and $\widehat{\lambda}_{2}$ denote the threshold estimates of the model with three regimes (equation 5), and $S_{2}\left(\hat{\lambda}_{1}, \hat{\lambda}_{2}\right)$ denotes the corresponding residual sum of squares. The hypothesis of one threshold is rejected in favor of two thresholds if $F_{2}$ is larger than the critical value of the non simulated distribution. The corresponding asymptotic p-value can be approximated by bootstrap simulations (Hansen, 1999). If the model with two thresholds (three regimes) is accepted, we propose to test the hypothesis of two thresholds (three regimes) against the alternative of three thresholds (four regimes). The corresponding likelihood ratio statistic, denoted $F_{3}$, is defined as:

$$
F_{3}=\frac{S_{2}\left(\widehat{\lambda}_{1}, \widehat{\lambda}_{2}\right)-S_{3}\left(\widehat{\lambda}_{1}, \widehat{\lambda}_{2}, \widehat{\lambda}_{3}\right)}{\widehat{\sigma}^{2}}
$$

\footnotetext{
${ }^{3}$ All the Matlab codes are available upon request.
} 
where $S_{3}\left(\hat{\lambda}_{1}, \hat{\lambda}_{2}, \widehat{\lambda}_{3}\right)$ denotes the residual sum of squares of the model with four regimes and three threshold parameters. In models with $m+1>2$ regimes, the estimates of the $m$ threshold parameters can be done sequentially by using the estimated threshold parameters obtained in the model with $m$ regimes as suggested by Bai and Perron (1998) in the context of multiple changepoint models. In this paper, we limit our analysis to a model with 4 regimes at the maximum given the computational cost of such models. Thus, a sequential procedure based on $F_{1}, F_{2}$ and $F_{3}$ allows to determining the number of regimes ${ }^{4}$.

The second issue consists of determining the threshold variable. Few technical constraints are imposed to the choice of the threshold variable. The only constraint is that the threshold variable can not be time invariant. Therefore, this choice is mainly an economic issue. If we want to assess the idea that the infrastructure investments have a network character, it implies that the threshold variable should be an indicator of the completion of the network. In this perspective, a natural candidate for the threshold variable is the existing level of available infrastructure. According to Fernald, a low level of capital (relatively to the population or to the workforce for instance) indicates that the construction of the network is not completed and may imply a high a productivity of stocks, and a high level of stocks may imply, if the network is built, a null or low marginal productivity. Two choices are then possible: the threshold variable can be defined as the level of infrastructure stock or as the level infrastructure stock per worker (or per capita). The second variable allow to avoid the scale effects in the network. Thus, our first specification is based on the following threshold variable:

$$
\text { Model A : } q_{i t}=x_{i t}
$$

Another solution for the threshold variable would consists in using the lagged level of GDP per worker, i.e. $q_{i t}=y_{i, t-1}$. It is necessary to use the lagged value of $y_{i t}$ in order to avoid a simultaneity since this variable is the endogenous variable of our regressions. This specification corresponds to a heterogeneity between "rich" and "poor "countries as suggested by Canning and Bennathan (2000). However, contrary to Canning and Bennathan, our heterogeneity is endogenous in the sense that it is the the threshold variable $y_{i, t-1}$ (and the threshold parameters $\lambda_{j}$ ) which determine the list of countries included in the different regimes of productivity. Besides, in our specification a country with low productivity (which belongs to regime 1 for instance) in the beginning of the period can have a medium or high productivity at the end of the sample period (i.e. belongs to the regime 2 or 3 ). Therefore, we consider a second model with:

$$
\text { Model B: } \quad q_{i t}=y_{i, t-1}
$$

\footnotetext{
${ }^{4}$ The codes for the estimation and inference procedures are done with Matlab. All codes are available upon request.
} 


\section{Data and Linear Models of Productivity}

We consider the same data as those used by Canning (1999) and Canning and Bennathan (2000). For output we use purchasing power parity ${ }^{5}$ GDP per worker (chain index). In both studies, physical capital stocks are constructed using a perpetual inventory method. The initial stock is obtained by assuming a capital-output ratio of $3 \%$ in the base year. The flows of investments are taken from the Penn World Tables 6.00. As Canning, we assume a constant depreciation rate of $7 \%$ for the private capital. Canning shows that his results are robust to variations in the initial choice of capitaloutput ratio and the depreciation rate. Finally, human capital per worker is taken to be the average years of schooling of the workforce. Given the data availability, the average years of schooling of the workforce is approximated here by the average years of schooling of the total population aged 15 and above ${ }^{6}$, from Barro and Lee (2000). Since these human capital data are available only every five years, Canning proposes to interpolate to give annual data.

We use four infrastructure capital stock variables: the number of telephones, kilowatts of electricity generating capacity and the length of paved roads and the railways line length, both expressed in kilometers. The infrastructure figures are the processed data from Canning (1998). The corresponding maximal sample is 1950-1995. As stated by Canning, these physical measures do not reflect the quality differences in infrastructure across countries and over time. The effectiveness of infrastructure may depend on its quality both initially and in terms of maintenance. But as noted by Canning, a simple fixed effect specification allows to capture a part of these cross country quality differences, more precisely the part which is constant over time. Consequently, in all our models, individual fixed effects are introduced.

The estimation of a threshold model requires the use of a balanced panel. For each specification, i.e. for each type of infrastructure, we select countries (among a total of 146 countries) for which we have a complete data set on the relevant variables over the longest period. The period of estimation is chosen in order to maximize the total number of observations. That is why, as in previous studies, the composition of our panel varies with the type infrastructure considered. For each specification, the sample used and the number of included countries are reported in Table 1. The countries can be divided in four groups: low income countries (LIC), lower middle income countries (LMI), upper middle income countries (UMI) and high income countries (HIC). These groups are based on World Bank definitions.

In order to asses the comparability of our data sets to the data sets used in previous studies, we first estimate the augmented production function in linear panel models. As in Calderon and Serven (2004), we propose simple estimators of the equation (2). The results are reported in Table 2. First, we consider a model in which the four infrastructures are simultaneously introduced in the production function. It can be seen

\footnotetext{
${ }^{5}$ It is important to note that in Penn World Tables, "real" means "PPP converted" instead of "in constant price".

${ }^{6}$ Variable code: TYR15, Barro and Lee (2000), "International Data on Educational Attainment: Updates and Implications", Harvard University, February 2000.
} 
that all regressors carry positive coefficients, all significantly different from zero ${ }^{7}$. The same qualitative results are obtained when the infrastructure variables are introduced separately (column 2 to 4). Our results are not directly comparable to that of Canning (1999), since $(i)$ he considers a specification with lead and lagged explanatory variables in order to obtain consistent estimates of the long-run parameters (Kao and Chiang, 2000), (ii) he considers only three types of infrastructures and (iii) his panel is not balanced and covers more countries than our data set. However, we can observe that the values of the various estimated parameters are roughly similar. In our sample, the estimated elasticity of physical capital is slightly greater than those obtained by Canning (0.37) with a panel of 57 countries in a specification with 2 lags and 1 lead. But, it is exactly the same value as those obtained by Canning in a model without leads and lags, and with only physical and human capital stocks as explanatory variables (table 32, page 11, Canning, 1999). Moreover, the estimated parameters $\gamma$ when the infrastructures are introduced one by one are similar to that reported by Canning and Bennathan (2000). For instance, the estimated parameter associated to the paved roads is 0.07 in our balanced sample of 50 countries whereas it is equal to 0.083 in the dynamic specification (2 lags, 1 lead) estimated by Canning and Bennathan in a panel of 67 countries. For electricity, our estimated parameter is 0.052 whereas their estimated parameter is equal to 0.085 and to 0.057 when electricity generating capacity is introduced simultaneously with the kilometers of paved roads.

Thus, our results of linear models based on the four balanced panels are quite similar to those generally obtained in the literature. Consequently, our selection procedure of countries can be considered as robust in the sense that it does not distort the estimates of productivity previously reported. Given these balanced panels, we now consider the estimation of the productivity of infrastructures when threshold effects are introduced.

\section{Threshold Models and Network Effects}

We now consider models in which the threshold variable is defined as the level of available infrastructure. The aim of this specification is to capture the network effects of the infrastructure in order to estimate robust rates of returns. As it was previously mentioned, the first step consists in determining the number of regimes, or equivalently in testing the threshold. For that, we consider the sequential procedure proposed by Hansen (1999). The model is estimated, allowing for sequentially zero, one, two and three thresholds. For each specification, the tests statistics $F_{1}, F_{2}$ and $F_{3}$ along with their bootstrap p-values are reported. The results of these tests for the model A, where the threshold variable $q_{i t}$ is defined as the infrastructure stock per worker $x_{i t}$, are reported in Table 3.

\footnotetext{
${ }^{7}$ We do not report here t-ratios based on the long-run auto-covariance matrix as in Canning (1999). Since, in the threshold models such corrected t-ratios are not computed, we choose to report the same t-statistics in linear and non linear models. Moreover, the t-ratios based on estimated long run variances with a Bartlett kernel and a common lag truncation parameter of 3 (as in Canning, 1999) give the same qualitative results, even the values of the t-ratios are smaller than those reported in Table 2.
} 
We find that the test for a single threshold $F_{1}$ is highly significant with a bootstrap p-value smaller than 0.001 for all the infrastructure variables considered. The lower value of the $F_{1}$ statistic is obtained for the telecommunication sector, but even in this case the value of the test statistic is largely below the critical values at standard levels. It implies that there is strong evidence that the relationship between output and the considered inputs is non-linear. As it was raised by Fernald (1999) or Gramlich (1994), the network aspect of infrastructure investments induces a strong non linearity in the productivity of these equipment and structures. The test for a double threshold $F_{2}$ is also strongly significant with a bootstrap p-value smaller than 0.001 . The last test for a third threshold $F_{3}$ is also significant, even if in this case the value of the Fstatistic is largely less important than those reported for the model with one or two thresholds. According to the Hansen's procedure, it would be necessary to pursue and to test for four thresholds, five thresholds etc. until the corresponding F-test is statistically not significant. However, as it was previously mentioned, we limit our analysis in this section to a model with at most three threshold parameters and four regimes. This choice is firstly justified by the computational cost of the estimation and inference procedures for panel models with more than 4 regimes. Secondly, we show that, given the sequential estimation procedure proposed by Hansen, when a supplementary regime is introduced, it does not affect (or slightly) the estimates of the other threshold parameters and the estimates of the slope parameters in the existing regimes. For instance, if we compare the estimated elasticities (and particularly that of infrastructure) obtained in a model with three regimes (see appendix A1) to the estimated elasticities obtained in a model with four regimes, we get similar results in the three existing regimes. For all these reasons, we limit our analysis to a model with three threshold parameters and four regimes in the relationships between output and capital stocks.

The estimates of the parameters of the PTR models with four regimes and the corresponding t-statistics based on corrected standard errors for heteroskedasticity are reported in Table 4. We use as threshold variable the infrastructure stock per worker (model A). In the electricity sector, the results clearly reflect the network dimension of the investments devoted to the electricity generating capacity. Indeed, we observe that when the electricity generating capacity per worker is very low (less than 32909 kilowatts per worker), the investments in this sector have the same productivity as the other private investments since the estimated parameter $\gamma$ is not significantly different from zero. On the contrary, when a minimum network is available, the marginal productivity of the electricity generating capacity is significantly and largely greater than to the productivity of the other investments. When the electricity generating capacity ranges from 32909 kilowatts per worker and 62536 kilowatts per worker, the estimated parameter $\gamma$ is equal to 0.295 . This value is largely greater than the values generally obtained in linear specifications in panel models. Recall that in our sample, the estimated parameter $\gamma$ obtained in a linear specification with individual effects and time effects was only equal to 0.05 (Table 2). It implies that if we do not take into account the non linearity of the relationship between infrastructure and output, the productive effect of these investments can be undervalued during the period of building of the network. When the network is near to be completed, i.e. when the capacity by 
worker ranges from 62536 and 595710 , the marginal productivity of infrastructure is always significantly greater than the productivity of other investments, but the value of the parameter $\gamma$ is smaller than in the previous regime. The estimated parameters falls from 0.29 to 0.12 , which is a value similar to that generally obtained in linear models (Canning, 1999; Calderon and Serven, 2004). This decrease of the naïve measure ${ }^{8}$ of the elasticity of infrastructures reflects the progressive maturity of the network and not only a standard argument of decreasing returns, which only implies a simple constraint on the position of this elasticity with respect to the unity. Finally, when the electricity generating capacity per worker exceeds 595710 kilowatts per worker, the productivity of investments in this sector becomes similar to the productivity of other investments. The estimated parameter $\gamma$ is slightly significantly different from zero, but relatively small compared to the value obtained in linear models. The t-statistic associated to the test of the nullity of $\gamma$ is in this case largely smaller than the value obtained in the regimes 2 or 3 . The productivity of infrastructure investment in the electricity sector is then slightly positive (or even null if we consider not corrected t-statistics) in the last regime. In other words, when the network is completed, the use of a linear specification may lead to overvalue the productivity of infrastructure when the network is achieved. It is exactly the idea pointed out by Fernald (1999) for the road network in the United States: the construction of the network booms substantially the productivity and the output, but when the construction of the network is completed, the public capital is not exceptionally productive at the margin. As it was previously mentioned, these results are robust when we consider a model with three regimes and two threshold parameters. The corresponding results for the model A $\left(q_{i t}=x_{i t}\right)$ are reported in Table A1 in appendix A1. We obtain roughly the same estimated elasticities as reported in a model with four regimes. The only difference is that the two intermediate regimes with the highest productivity are now replaced by only one regime with an estimated parameter $\gamma$ equal to 0.127

As far as the road sector is concerned, the productivity of infrastructures also exhibits strong network effects when the threshold variable is defined as the number of kilometers of paved road per worker (Table 4). As for in previous case, we observe a profile low - high - low for the productivity given the regimes. When the paved road length actually available is very low, smaller than 0.36 kilometers per worker, the parameter $\gamma$ is significantly positive and greater than the value obtained in a linear specification (Table 2). But, when the network is more important (regime 3), the value of this parameter is greater and increases from 0.13 to 0.15 . On the contrary, when the network is completed or near to be completed, the value of the naïve elasticity decreases to 0.12 , but is still significantly different from zero, contrary to the electricity sector. It is highly probable that in a model with more than four regimes, an extreme regime would appear with a smaller value for $\gamma$ in which some industrialized countries would appear. Finally, the last difference with the electricity sector is that an intermediate regime appears in the model with four regimes in which the estimated parameter $\gamma$ is negative and significantly different from zero. As noted by Canning (1999) the correct interpretation of the coefficient on the infrastructure variable represents the

\footnotetext{
${ }^{8}$ Which is probably near to the true elasticity value, as pointed out by Calderon and Serven (2004).
} 
output effect of increasing infrastructure capital while holding overall physical capital constant. "That is, we measure the effect as an increase in infrastructure assuming an equal (measured of terms of the cost of investment) offsetting decrease in other forms of capital" (Canning, 1999, page 12). When this offset has a negative impact on the GDP per worker, it implies that the marginal productivity of infrastructure capital is less important than the marginal productivity of other capital. Thus, in the intermediate regime 2, the marginal productivity of road infrastructure is smaller than the productivity of other capital. However, this result is not robust when we consider a model with three regimes (Table A1, appendix A1). In this case, we still observe the low high - low productivity profile, but the intermediate regime with a negative value of $\gamma$ disappears.

For the telecommunication sector, the results are similar and also reveal strong threshold effects. In this case, the threshold variable is defined as the number of telephones by worker. When the network is not important, the infrastructure investments in the telecommunication sector have the same productivity as the other forms of capital. When the network is more important their productivity increase. In the second regime, the estimated parameter $\gamma$ is then greater than 0.20 , whereas it is only equal to 0.10 in a linear specification (see Table 2). In the third regime, the value of $\gamma$ falls to 0.12 as it is suggested in the Fernald's analysis. However, when the telecommunication network is largely developed, with more than 126 telephones per worker, this kind of investments has another regime of high productivity. This particular regime is undoubtedly linked to the importance of the telecommunications networks in the post-industrialized countries included in our sample.

Finally, the results are less clear when we consider the railways sector. In this case, the regime of high productivity is found when the network is largely incomplete with less than 0.24 kilometers of railways per worker. When the network is more important, the estimated parameter $\gamma$ becomes null or even negative. This particular evolution of the productivity of railways can be explained by the substitution of this mean of transport by other means of transport in the developing countries. After the building of the main lines between the main urban areas of the countries, the productivity of railways investments falls (comparatively to other means of transport) when ones comes to build the secondary network between the less important urban areas. Consequently, compared to the road sector for instance, the decline of the marginal productivity due to the network completion is more rapidly achieved.

\section{Threshold Models and Income Heterogeneity}

As it was previously mentioned, the threshold effects in the productivity can also be induced by the heterogeneity of the production structure between the countries of our sample. The idea is that the marginal productivity of the same infrastructure may not be equivalent for rich countries and poor countries: this heterogeneity may be the consequence of various network effects (which depend on the completion of the main infrastructure networks, and not only on the completion on the considered 
infrastructure network), but also of many other reasons (the heterogeneity of the level and the quality of private capital, the heterogeneity in the economic systems etc.). So, we propose to consider a threshold specification of the production function in which the threshold variable is defined by the lagged level of real GDP per worker, i.e. $q_{i t}=y_{i, t-1}$ (Model B).

It is important to note that the specification of a threshold production function, where the threshold variable is defined as the level of lagged GDP per worker can be considered as a technical solution to circumvent the reverse causation problem. Indeed, in linear specification the correlation between infrastructure stocks and the productivity of private capital may reflect causation from the changes in the stock to changes in productivity. In other words, the infrastructure stocks are likely to be endogenous. This point has been largely document in the literature devoted to the measure of the productivity public capital (Gramlich, 1994). It generally leads to the use of instrumental variable methods (GMM, simultaneous equations etc.). In our threshold specification, the correlation between GDP per worker and infrastructure stocks is conditional to the level of the GDP per worker observed in the past period. Thus, if the infrastructure level is linearly linked to the GDP, the reverse causation would imply a number of regimes identical to the number of possible values of the GDP. If the number of regime is restricted, the influence of the reverse causation in each regime would be less important than in a linear representation and may be ignored if the number of regimes is sufficiently large. A similar observation can be done for the other specifications as soon as the threshold variable is correlated with the level of the lagged GDP.

As in the previous case, the first step of the Hansen estimation procedure consists in determining the number of regimes which must be adopted in the estimation of the production function. For that, the model is estimated, allowing for sequentially zero, one, two and three thresholds. For each specification, the statistics $F_{1}, F_{2}$ and $F_{3}$ along with their bootstrap p-values are reported. The results of these tests for the model $\mathrm{B}$ are reported in Table 5. First, we can observe that whatever the hypothesis tested, the values of the F-tests are largely greater than those obtained in the case of the model A (see Table 2). It clearly indicates that the threshold effects (and the rejection of the linearity assumption) are largely more important when we consider the per worker income heterogeneity than when we consider the network effects of infrastructures. Secondly and consequently, in all specifications the F-tests lead to the conclusion that there are more than 4 regimes in the production function given the level of the lagged value of the real GDP per capita. However, for the same reasons as exposed in the case of the model A, we limit our analysis to a model with at most four regimes.

The estimates of the parameters of the PTR models with four regimes and the corresponding t-statistics based on corrected standard errors for heteroskedasticity are reported in Table 6 . The three threshold estimates (defined on the GDP per worker) identify four production functions and four separate groups of countries. The four regimes can be interpreted as four separated groups of countries as in the World Bank classification: "lower income", "lower middle income", "upper middle income" and "high income" countries. However, the distribution of the countries in these groups is 
endogenous and not time invariant since it may evolve given the level of the GDP per worker. Globally, in all sectors we can observe that the estimated parameters $\gamma$ are generally positive and significant in each group of countries. One exception is the case of the road sector in the last regime (high income countries), in which this parameter becomes not significant at $5 \%$ level. This result is compatible with the conclusions of Fernald (1999) for the road sector in the United States, if we admit that when a country is in this last regime, its road network is generally achieved. More surprisingly, the values of the parameters $\gamma$ are quite similar in all the regimes, compared to the values obtained when the threshold variable was defined as the amount of infrastructure available per worker. It is particularly true for the telecommunication sector, where the parameter $\gamma$ ranges from 0.13 to 0.18 in the four groups of countries and for the road sector in the first three groups of countries. This result implies that the heterogeneity of the productivity of infrastructure is less important when we regroup the countries according to their GDP per worker than we consider groups according to the amount of infrastructure per worker actually available. In other words, the heterogeneity seems to be more related to the network effect than to the level of per capita income, even if this last measure is sometimes (but not always) a proxy of the completion of the network. The network effects seem to be more important to explain the non linearity of the marginal productivity of infrastructures than the threshold effects based on the income heterogeneity.

\section{Conclusion}

In this paper we provide an empirical evaluation of the threshold effects of the productivity of infrastructures and public capital stocks in developing countries. Our assessment is based on the estimation of various threshold panel specifications of infrastructure or public capital augmented production functions. More precisely, we consider various specifications of a Panel Threshold Regression (PTR) model (Hansen, 1999) in which the individual parameters of the augmented production functions are divided into a small number of groups according to an observable variable. The transition mechanism between the different regimes of productivity is then determined by the level of a threshold variable. If the threshold variable exceeds a certain value, the production technology switches from one regime to another. Our main results can be summarized in two main points.

First, the relationship between the output and the infrastructure stocks is non linear. More precisely, strong threshold effects can be identified in these relationships. This conclusion is robust to changes in the panel model used, in the testing procedure applied and to changes in the composition of the panel sample. These threshold effects are clearly identified when physical measures of the infrastructure stocks actually available in the country per worker are used as threshold variable. Second, the productivity of infrastructure (road, electricity, telephones and railways) exhibits strong threshold effects which could be interpreted as network effects. In a first step, when the stock of infrastructure in a sector actually available per worker is very low, the infrastructure investments in this sector have the same productivity as the other investments. On the 
contrary, when the network is sufficiently developed but not achieved, the infrastructure investments have a productivity which is generally largely higher than the productivity of other investments. Finally, when the level of physical infrastructure stock per worker exceeds a certain value indicating that the main network is achieved, the productivity rapidly decreases and the infrastructure investments may be not exceptionally productive at the margin. In other words, the highest marginal productivity of investments is reached when a network is sufficiently developed, but not completely achieved.

Therefore, these threshold effects are an argument in favour of the sectorial specialization of the public investments in infrastructure in developing countries. This specialization may be less important in the industrialized countries in which infrastructure networks are already available (water, sewer, road, rail, electricity, telecommunications etc.). On the contrary, this specialization of infrastructure investments may be essential in developing countries where none of these main networks is near to be operational. In this case, one or two particular infrastructure networks have to be considered as a priority compared to all other infrastructure networks, and the majority of investments must be devoted to these priority sectors. In the poorest developing countries, it could be the case for the water distribution and sanitation systems, for instance as suggested by some many recent programs lead by the international institutions. This idea of a specialization of infrastructure investments may be compared to the idea of a universal primary service, as for instance the universal primary education service supported by the Education for All (EFA) international commitment (1990, 2000). In this context, the goal is to ensure a primary education for all children in developing countries before investing in the secondary education and more evidently in the university system which would benefit only to a minority of the population. The mechanism is exactly the same in our network perspective: the highest marginal productivity of investments is reached when a network (primary education buildings) is sufficiently developed, but not completely achieved. During this period it would be inappropriate to begin investments in another network (university facilities) for which the marginal productivity may be very low.

\section{A Appendix}

\section{A.1 Threshold Models with Three Regimes}

In order to asses the sensitivity of our results to the choice of the number of regimes, we report on the Tables A1 and A2 the results of the estimation of the Models A and $\mathrm{B}$ with three regimes (two threshold parameters). 


\section{B References}

Ai, C. And Cassou, S.P. (1995), "A Normative Analysis of Public Capital", Applied Economics, 27, pp. 1201-1209.

Aschauer, D.A. (1989), "Is Public Expenditure Productive?", Journal of Monetary Economics 23, pp. 177-200.

Bai, J. And Perron, P. (1998), "Estimating and Testing Linear Models with Multiple Structural Changes", Econometrica, 66, pp. 47-78.

Baltagi, B.H. And Pinnoi, N. (1995), "Public Capital Stock and State Productivity Growth: Further Evidence from an Error Components Model", Empirical Economics, 20(2), pp. 351-359.

Barro, R.J. And Lee, J.W. (2000), "International Data on Educational Attainment Updates and Implications", NBER Working Paper W7911.

Calderon, C. And Serven, L. (2004), "The Output Cost of Latin America's Infrastructure Gap", in The Limits of Stabilization, Easterly W. and Serven L. eds., The World Bank.

Calderon, C., Easterly, W. and Serven, L. (2004), "Latin America's Infrastructure in the Era of Macroeconomic Crises", in The Limits of Stabilization, Easterly W. and Serven L. eds., The World Bank.

Canning, D. (1998), "A Database of World Infrastructure Stocks, 1950-1995", The World Bank Economic Review, 12, 529-547.

Canning, D. (1999), "Infrastructure's Contribution to Aggregate Output", The World Bank, Policy Research Working Paper Series, 2246.

Canning, D. and Bennathan, E. (2000), "The Social Rate of Return on Infrastructure Investments", The World Bank, Policy Research Working Paper Series, 2390.

Canning, D. And Pedroni, P. (1999), "Infrastructure and Long Run Economic Growth", CAER Discussion Papers, 57.

Crowder, W.J., And Himarios, D. (1997), "Balanced Growth and Public Capital: an Empirical Analysis", Applied Economics, 29, pp. 1045-1053.

Demetrias, P. And Mamuneas, T (2000), "Intertemporal Output and Employment Effects of Public Infrastructure Capital: Evidence from 12 OECD Economies", Economic Journal, 110, pp. 687-712.

Evans, P. And Karras, G. (1994), "Is Government Capital Productive? Evidence from a Panel of Seven Countries", Journal of Macroeconomics, 16(2), pp. 271-279.

Fernald, J.G. (1999), "Roads to Prosperity? Assessing the Link Between Public Capital and Productivity", The American Economic Review, 89(3), pp. 619-638.

Finn, M. (1993), "Is All Government Capital Productive?", Federal Reserve Bank of Richmond, Economic Quarterly, 79(4), pp. 53-80.

Gramlich, E.M. (1994), "Infrastructure Investment: a Review Essay", Journal of Economic Literature, 32, pp. 1176-1196. 
Hansen, B.E. (1996), "Inference when a Nuisance Parameter is not identified under the Null Hypothesis", Econometrica, 64, pp. 413-430.

Hansen, B.E. (1999), "Threshold Effects in Non-Dynamic panels: Estimation, Testing and Inference", Journal of Econometrics, 93, pp. 345-368.

Holtz-Eakin, D. (1994), "Public-Sector Capital and the Productivity Puzzle", The Review of Economics and Statistics, 76, pp. 12-21.

Im, K.S., Pesaran, M.H., and Shin, Y. (2003), "Testing for Unit Roots in Heterogeneous Panels", Journal of Econometrics, 115, 1, 53-74.

Kao, C. And Chiang, M.H. (2000), "On the Estimation and Inference of a Cointegrated Regression in Panel Data", Nonstationary panels, panel cointegration, and dynamic panels, 2000, pp. 179-222.

Kamps C. (2004), The Dynamic Macroeconomic Effects of Public Capital: Theory and Evidence for OECD Countries, Springer.

Otтo G.D. And Voss G.M. (1998), "Is Public Capital Provision Efficient?", Journal of Monetary Economics, 42, pp. 47-66.

Pedroni, P. (1999), "Critical Values for Cointegration Tests in Heterogeneous Panels with Multiple Regressors", Oxford Bulletin of Economics and Statistics, 61, p. 653-670.

Romp, W. And De HaAn, J. (2005), "Public Capital and Economic Growth: A critical Survey", Mimeo, University of Groningen.

Sturm, J.E., And De HaAn, J. (1995), "Is Public Expenditure Really Productive?", Economic Modelling, 12, pp. 60-72.

Summers, R., And Heston, A., (1991), "The Penn World Tables (Mark 5): An Expanded set of International Comparisons, 1950-88", Quarterly Journal of Economics, 106(2), pp. 327-368.

Swamy, P.A. (1970), "Efficient Inference in a Random Coefficient Regression Model", Econometrica, 38, pp. 311-323.

Tatom, J.A. (1991), "Public Capital and Private Sector Performance", Federal Reserve Bank of Saint-Louis Review, 73, pp. 3-17. 
Table 1. Sample Properties

\begin{tabular}{lcccccccc}
\hline \hline & Sample & $\mathrm{N}$ & $\mathrm{T}$ & Obs. & LIC & LMI & UMI & HIC \\
\hline Paved Roads & $1965-1990$ & 50 & 26 & 1300 & 13 & 12 & 9 & 16 \\
Electricity Capacity & $1961-1995$ & 76 & 35 & 2660 & 17 & 22 & 11 & 26 \\
Number of Telephones & $1961-1990$ & 56 & 30 & 1680 & 15 & 18 & 12 & 11 \\
Railways & $1960-1992$ & 57 & 33 & 1881 & 9 & 18 & 8 & 22 \\
All Types of Infrastructure & $1965-1990$ & 24 & 26 & 624 & 5 & 9 & 5 & 5 \\
\hline \hline
\end{tabular}

Notes: The value of Obs. denotes the total number of observations in the balanced panel. The values of LIC, LMI, UMI and HIC correspond respectively to the number of Low Income Countries, Lower Middle Income countries, Upper Middle Income countries and High Income Countries included in the sample.

Table 2. Infrastructure Augmented Production Function Linear Panel Models with Fixed Effects and Year Dummies

\begin{tabular}{lccccc}
\hline \hline \multicolumn{1}{c}{ Within Estimates } & Model 1 & Model 2 & Model 3 & Model 4 & Model 5 \\
\hline Physical Capital & 0.473 & 0.616 & 0.529 & 0.460 & 0.576 \\
Human Capital & $(12.4)$ & $(44.4)$ & $(49.0)$ & $(31.32)$ & $(47.7)$ \\
& 0.143 & 0.131 & 0.104 & 0.109 & 0.207 \\
Roads & $(4.55)$ & $(7.06)$ & $(7.42)$ & $(6.28)$ & $(10.37)$ \\
Electricity & 0.078 & 0.070 & - & - & - \\
Telephones & $(3.72)$ & $(7.20)$ & & & - \\
Railways & 0.096 & - & 0.052 & - & - \\
RSS & $(4.89)$ & & $(6.09)$ & & -104 \\
Number of observations & 0.041 & - & - & $(7.42)$ & \\
Number of countries & $(1.377)$ & & & - & 0.192 \\
& 0.063 & - & - & & $(11.19)$ \\
\hline \hline
\end{tabular}

Notes: Dependent variable is log GDP per worker. All variables are measured per worker and expressed in logs. The t-statistics are in parenthesis. 
Table 3. Tests for Threshold Effects: Model A, $q_{i t}=x_{i t}$

\begin{tabular}{lcccc}
\hline \hline & Roads & Electricity & Telephones & Railways \\
\hline Test for single threshold & & & & \\
$F_{1}$ & 90.2 & 112.1 & 59.5 & 128.4 \\
P-value & 0.00 & 0.00 & 0.00 & 0.00 \\
$1 \%$ Critical Values & 13.7 & 14.3 & 14.3 & 14.9 \\
$5 \%$ Critical Values & 15.3 & 15.5 & 16.8 & 16.5 \\
$10 \%$ Critical Values & 19.3 & 20.6 & 22.0 & 21.3 \\
Test for double threshold & & & & \\
$F_{2}$ & 84.7 & 74.3 & 82.6 & 122.6 \\
P-value & 0.00 & 0.00 & 0.00 & 0.00 \\
$1 \%$ Critical Values & 50.4 & 19.8 & 17.2 & 30.7 \\
$5 \%$ Critical Values & 55.2 & 22.7 & 19.2 & 36.9 \\
$10 \%$ Critical Values & 68.2 & 26.2 & 25.1 & 42.2 \\
Test for triple threshold & & & & \\
$F_{3}$ & 41.7 & 43.8 & 55.7 & 85.9 \\
P-value & 0.00 & 0.00 & 0.00 & 0.00 \\
$1 \%$ Critical Values & 13.6 & 13.6 & 13.6 & 13.2 \\
$5 \%$ Critical Values & 15.2 & 15.6 & 15.7 & 15.5 \\
$10 \%$ Critical Values & 18.0 & 21.2 & 19.2 & 18.4 \\
\hline \hline
\end{tabular}

Notes: P-values and critical values are computed from 300 simulations. F1 denotes the Fisher type statistic associated to the test of the null of no threshold against one threshold. F2 corresponds to the test one threshold against two thresholds and F3 corresponds to the test of two thresholds against three thresholds. 
Table 4. Four Regimes Panel Models. Model A: $q$ it $=x_{i t}$

\begin{tabular}{|c|c|c|c|c|}
\hline & Roads & Electricity & Telephones & Railways \\
\hline \multicolumn{5}{|l|}{ Regime 1: $q_{i t} \leq \lambda_{1}$} \\
\hline Physical Capital per Worker & $\begin{array}{c}0.593 \\
(38.4)\end{array}$ & $\begin{array}{c}0.520 \\
(30.1)\end{array}$ & $\begin{array}{c}0.417 \\
(24.6)\end{array}$ & $\begin{array}{c}0.612 \\
(49.1)\end{array}$ \\
\hline Human Capital per Worker & $\begin{array}{l}0.046 \\
(2.44)\end{array}$ & $\begin{array}{c}0.165 \\
(10.2)\end{array}$ & $\begin{array}{c}0.062 \\
(2.43)\end{array}$ & $\begin{array}{l}0.564 \\
(21.5)\end{array}$ \\
\hline Infrastructure per Worker & $\begin{array}{l}0.131 \\
(5.51)\end{array}$ & $\begin{array}{l}0.001 \\
(0.08)\end{array}$ & $\begin{array}{l}-0.030 \\
(-0.73)\end{array}$ & $\begin{array}{c}0.183 \\
(7.51)\end{array}$ \\
\hline \multicolumn{5}{|l|}{ Regime 2: $\lambda_{1}<q_{i t} \leq \lambda_{2}$} \\
\hline Physical Capital per Worker & $\begin{array}{c}0.496 \\
(24.5)\end{array}$ & $\begin{array}{c}0.629 \\
(29.0)\end{array}$ & $\begin{array}{l}0.384 \\
(22.4)\end{array}$ & $\begin{array}{c}0.600 \\
(50.0)\end{array}$ \\
\hline Human Capital per Worker & $\begin{array}{l}0.194 \\
(6.52)\end{array}$ & $\begin{array}{c}0.179 \\
(6.60)\end{array}$ & $\begin{array}{c}0.120 \\
(6.94)\end{array}$ & $\begin{array}{c}0.398 \\
(16.3)\end{array}$ \\
\hline Infrastructure per Worker & $\begin{array}{c}-0.676 \\
(-5.44)\end{array}$ & $\begin{array}{l}0.295 \\
(6.56)\end{array}$ & $\begin{array}{l}0.210 \\
(13.8)\end{array}$ & $\begin{array}{c}-0.070 \\
(-1.64)\end{array}$ \\
\hline \multicolumn{5}{|l|}{ Regime 3: $\lambda_{2}<q_{i t} \leq \lambda_{3}$} \\
\hline Physical Capital per Worker & $\begin{array}{c}0.580 \\
(39.8)\end{array}$ & $\begin{array}{c}0.591 \\
(41.9)\end{array}$ & $\begin{array}{l}0.453 \\
(17.7)\end{array}$ & $\begin{array}{l}0.624 \\
(51.7)\end{array}$ \\
\hline Human Capital per Worker & $\begin{array}{l}0.219 \\
(12.8)\end{array}$ & $\begin{array}{l}0.071 \\
(4.46)\end{array}$ & $\begin{array}{c}-0.127 \\
(-3.42)\end{array}$ & $\begin{array}{l}0.230 \\
(11.8)\end{array}$ \\
\hline Infrastructure per Worker & $\begin{array}{c}0.155 \\
(7.42)\end{array}$ & $\begin{array}{c}0.126 \\
(11.7)\end{array}$ & $\begin{array}{l}0.129 \\
(2.81)\end{array}$ & $\begin{array}{c}-0.158 \\
(-6.42)\end{array}$ \\
\hline \multicolumn{5}{|l|}{ Regime 4: $q_{i t}>\lambda_{3}$} \\
\hline Physical Capital per Worker & $\begin{array}{c}0.590 \\
(36.6)\end{array}$ & $\begin{array}{c}0.556 \\
(39.3)\end{array}$ & $\begin{array}{l}0.365 \\
(17.1)\end{array}$ & $\begin{array}{c}0.524 \\
(32.7)\end{array}$ \\
\hline Human Capital per Worker & $\begin{array}{l}0.099 \\
(3.62)\end{array}$ & $\begin{array}{c}0.256 \\
(9.91)\end{array}$ & $\begin{array}{l}0.116 \\
(3.22)\end{array}$ & $\begin{array}{l}0.717 \\
(15.4)\end{array}$ \\
\hline Infrastructure per Worker & $\begin{array}{c}0.122 \\
(4.58)\end{array}$ & $\begin{array}{c}0.035 \\
(2.41)\end{array}$ & $\begin{array}{l}0.226 \\
(12.25)\end{array}$ & $\begin{array}{c}-0.014 \\
(-0.36)\end{array}$ \\
\hline \multicolumn{5}{|l|}{ Threshold Estimates } \\
\hline First Threshold $\widehat{\lambda}_{1}$ & -1.021 & -3.414 & 1.445 & -1.427 \\
\hline Second Threshold $\widehat{\lambda}_{2}$ & -0.642 & -2.772 & 4.314 & -0.861 \\
\hline Third Threshold $\widehat{\lambda}_{3}$ & 1.249 & -0.518 & 4.839 & 0.975 \\
\hline Residual Sum of Squares & 12.4 & 42.4 & 23.3 & 26.6 \\
\hline
\end{tabular}

Notes: The t-statistics in parenthesis are computed with an estimator of the covariance matrix which allows for heteroskedasticity. The confidence intervals for the threshold parameters are not reported. See Appendix A1, for the confidence intervals in a model with three regimes. 
Table 5. Tests for Threshold Effects: Model B, $q_{i t}=y_{i, t-1}$

\begin{tabular}{lcccc}
\hline \hline & Roads & Electricity & Telephones & Railways \\
Test for single threshold $F_{1}$ & 172.4 & 324.5 & 201.0 & 495.6 \\
P-value & 0.00 & 0.00 & 0.00 & 0.00 \\
Test for double threshold $F_{2}$ & 198.9 & 319.9 & 200.4 & 363.4 \\
P-value & 0.00 & 0.00 & 0.00 & 0.00 \\
Test for triple threshold $F_{3}$ & 181.4 & 324.2 & 204.2 & 165.6 \\
P-value & 0.00 & 0.00 & 0.00 & 0.00 \\
\hline \hline
\end{tabular}

Notes: P-values are computed from 300 simulations. F1 denotes the Fisher type statistic associated to the test of the null of no threshold against one threshold. F2 corresponds to the test one threshold against two thresholds and F3 corresponds to the test of two thresholds against three thresholds. 
Table 6. Four Regimes Panel Models. Model B: $q$ it $=y_{i, t-1}$

\begin{tabular}{|c|c|c|c|c|}
\hline & Roads & Electricity & Telephones & Railways \\
\hline \multicolumn{5}{|l|}{ Regime 1: $q_{i t} \leq \lambda_{1}$} \\
\hline Physical Capital per Worker & $\begin{array}{l}0.500 \\
(32.9)\end{array}$ & $\begin{array}{l}0.390 \\
(29.2)\end{array}$ & $\begin{array}{l}0.319 \\
(19.1)\end{array}$ & $\begin{array}{l}0.515 \\
(40.6)\end{array}$ \\
\hline Human Capital per Worker & $\begin{array}{l}0.085 \\
(4.71)\end{array}$ & $\begin{array}{l}0.152 \\
(12.4)\end{array}$ & $\begin{array}{l}0.050 \\
(1.87)\end{array}$ & $\begin{array}{l}0.450 \\
(21.5)\end{array}$ \\
\hline Infrastructure per Worker & $\begin{array}{c}0.061 \\
(3.11)\end{array}$ & $\begin{array}{l}0.037 \\
(3.96)\end{array}$ & $\begin{array}{c}0.179 \\
(8.11)\end{array}$ & $\begin{array}{c}0.035 \\
(1.88)\end{array}$ \\
\hline \multicolumn{5}{|l|}{ Regime 2: $\lambda_{1}<q_{i t} \leq \lambda_{2}$} \\
\hline Physical Capital per Worker & $\begin{array}{l}0.526 \\
(35.1)\end{array}$ & $\begin{array}{l}0.464 \\
(35.8)\end{array}$ & $\begin{array}{l}0.355 \\
(22.6)\end{array}$ & $\begin{array}{l}0.582 \\
(46.2)\end{array}$ \\
\hline Human Capital per Worker & $\begin{array}{l}0.063 \\
(3.52)\end{array}$ & $\begin{array}{l}-0.023 \\
(-1.31)\end{array}$ & $\begin{array}{l}0.053 \\
(2.56)\end{array}$ & $\begin{array}{l}0.172 \\
(6.76)\end{array}$ \\
\hline Infrastructure per Worker & $\begin{array}{l}0.081 \\
(5.07)\end{array}$ & $\begin{array}{c}0.102 \\
(9.81)\end{array}$ & $\begin{array}{l}0.135 \\
(7.37)\end{array}$ & $\begin{array}{c}0.051 \\
(3.36)\end{array}$ \\
\hline \multicolumn{5}{|l|}{ Regime 3: $\lambda_{2}<q_{i t} \leq \lambda_{3}$} \\
\hline Physical Capital per Worker & $\begin{array}{l}0.552 \\
(37.1)\end{array}$ & $\begin{array}{l}0.475 \\
(35.8)\end{array}$ & $\begin{array}{l}0.391 \\
(22.8)\end{array}$ & $\begin{array}{l}0.630 \\
(49.8)\end{array}$ \\
\hline Human Capital per Worker & $\begin{array}{l}0.073 \\
(3.17)\end{array}$ & $\begin{array}{c}-0.033 \\
(-1.30)\end{array}$ & $\begin{array}{l}-0.068 \\
(-3.28)\end{array}$ & $\begin{array}{l}-0.027 \\
(-1.27)\end{array}$ \\
\hline Infrastructure per Worker & $\begin{array}{c}0.071 \\
(4.95)\end{array}$ & $\begin{array}{l}-0.007 \\
(-0.57)\end{array}$ & $\begin{array}{c}0.166 \\
(12.2)\end{array}$ & $\begin{array}{l}0.053 \\
(3.96)\end{array}$ \\
\hline \multicolumn{5}{|l|}{ Regime 4: $q_{i t}>\lambda_{3}$} \\
\hline Physical Capital per Worker & $\begin{array}{l}0.591 \\
(37.8)\end{array}$ & $\begin{array}{l}0.503 \\
(39.7)\end{array}$ & $\begin{array}{l}0.428 \\
(23.2)\end{array}$ & $\begin{array}{l}0.653 \\
(50.8)\end{array}$ \\
\hline Human Capital per Worker & $\begin{array}{l}-0.041 \\
(-1.68)\end{array}$ & $\begin{array}{l}-0.007 \\
(-2.76)\end{array}$ & $\begin{array}{l}-0.170 \\
(-6.29)\end{array}$ & $\begin{array}{c}-0.087 \\
(-3.38)\end{array}$ \\
\hline Infrastructure per Worker & $\begin{array}{l}0.028 \\
(1.89)\end{array}$ & $\begin{array}{l}0.114 \\
(7.80)\end{array}$ & $\begin{array}{l}0.158 \\
(11.7)\end{array}$ & $\begin{array}{c}0.042 \\
(2.95)\end{array}$ \\
\hline \multicolumn{5}{|l|}{ Threshold Estimates } \\
\hline First Threshold $\widehat{\lambda}_{1}$ & 7.838 & 8.325 & 7.833 & 8.530 \\
\hline Second Threshold $\widehat{\lambda}_{2}$ & 8.332 & 9.234 & 8.291 & 9.076 \\
\hline Third Threshold $\widehat{\lambda}_{3}$ & 9.222 & 9.674 & 9.234 & 9.602 \\
\hline Residual Sum of Squares & 8.6 & 30.2 & 17.1 & 17.2 \\
\hline
\end{tabular}

Notes: The t-statistics in parenthesis are computed with an estimator of the covariance matrix which allows for heteroskedasticity. The confidence intervals for the threshold parameters are not reported. See Appendix A1, for the confidence intervals in a model with three regimes 
Table A1. Three Regimes Panel Models. Model A: $q$ it $=x_{i t}$

\begin{tabular}{|c|c|c|c|c|}
\hline & Roads & Electricity & Telephones & Railways \\
\hline \multicolumn{5}{|l|}{ Regime 1: $q_{i t} \leq \lambda_{1}$} \\
\hline Physical Capital per Worker & $\begin{array}{l}0.604 \\
(40.3)\end{array}$ & $\begin{array}{c}0.522 \\
(36.7)\end{array}$ & $\begin{array}{c}0.422 \\
(26.7)\end{array}$ & $\begin{array}{c}0.620 \\
(52.9)\end{array}$ \\
\hline Human Capital per Worker & $\begin{array}{c}0.078 \\
(4.21)\end{array}$ & $\begin{array}{l}0.165 \\
(10.9)\end{array}$ & $\begin{array}{c}0.099 \\
(5.95)\end{array}$ & $\begin{array}{l}0.453 \\
(19.6)\end{array}$ \\
\hline Infrastructure per Worker & $\begin{array}{l}0.138 \\
(5.34)\end{array}$ & $\begin{array}{c}0.012 \\
(0.81)\end{array}$ & $\begin{array}{c}0.207 \\
(14.9)\end{array}$ & $\begin{array}{l}0.135 \\
(6.73)\end{array}$ \\
\hline \multicolumn{5}{|l|}{ Regime 2: $\lambda_{1}<q_{i t} \leq \lambda_{2}$} \\
\hline Physical Capital per Worker & $\begin{array}{c}0.591 \\
(42.2)\end{array}$ & $\begin{array}{l}0.584 \\
(41.9)\end{array}$ & $\begin{array}{l}0.493 \\
(18.5)\end{array}$ & $\begin{array}{l}0.629 \\
(52.9)\end{array}$ \\
\hline Human Capital per Worker & $\begin{array}{c}0.239 \\
(14.1)\end{array}$ & $\begin{array}{l}0.072 \\
(4.69)\end{array}$ & $\begin{array}{c}-0.170 \\
(-4.46)\end{array}$ & $\begin{array}{l}0.256 \\
(13.0)\end{array}$ \\
\hline Infrastructure per Worker & $\begin{array}{l}0.145 \\
(8.82)\end{array}$ & $\begin{array}{l}0.127 \\
(11.9)\end{array}$ & $\begin{array}{c}0.128 \\
(2.53)\end{array}$ & $\begin{array}{c}-0.139 \\
(-5.56)\end{array}$ \\
\hline \multicolumn{5}{|l|}{ Regime 3: $q_{i t}>\lambda_{3}$} \\
\hline Physical Capital per Worker & $\begin{array}{l}0.604 \\
(38.4)\end{array}$ & $\begin{array}{c}0.550 \\
(39.3)\end{array}$ & $\begin{array}{l}0.414 \\
(20.5)\end{array}$ & $\begin{array}{c}0.532 \\
(33.2)\end{array}$ \\
\hline Human Capital per Worker & $\begin{array}{l}0.096 \\
(3.48)\end{array}$ & $\begin{array}{l}0.254 \\
(9.84)\end{array}$ & $\begin{array}{c}0.124 \\
(3.47)\end{array}$ & $\begin{array}{l}0.731 \\
(15.3)\end{array}$ \\
\hline Infrastructure per Worker & $\begin{array}{l}0.114 \\
(4.23)\end{array}$ & $\begin{array}{l}0.040 \\
(2.75)\end{array}$ & $\begin{array}{l}0.195 \\
(10.85)\end{array}$ & $\begin{array}{c}-0.007 \\
(-0.17)\end{array}$ \\
\hline \multicolumn{5}{|l|}{ Threshold Estimates } \\
\hline First Threshold $\widehat{\lambda}_{1}$ & -1.105 & -2.773 & 4.808 & -0.863 \\
\hline 95\% Confidence Interval & {$[-1.13,-0.99]$} & {$[-3.16,-2.73]$} & {$[4.78,4.84]$} & {$[-0.88,-0.82]$} \\
\hline Second Threshold $\widehat{\lambda}_{2}$ & 1.249 & -0.518 & 4.314 & 0.975 \\
\hline 95\% Confidence Interval & {$[1.10,1.38]$} & {$[-0.60,-0.13]$} & {$[4.11,4.35]$} & {$[0.91,0.99]$} \\
\hline Residual Sum of Squares & 12.8 & 43.1 & 24.1 & 27.9 \\
\hline
\end{tabular}

Notes: The t-statistics in parenthesis are computed with an estimator of the covariance matrix which allows for heteroskedasticity. The confidence interval for the threshold parameters corresponds to the no rejection region of confidence level $95 \%$ associated to the likelihood ratio statistic for test on the values of the threshold parameters (see Hansen, 1999). This confidence interval can be not symetric. 
Table A2. Three Regimes Panel Models. Model B: $q$ it $=y_{i, t-1}$

\begin{tabular}{|c|c|c|c|c|}
\hline & Roads & Electricity & Telephones & Railways \\
\hline \multicolumn{5}{|l|}{ Regime 1: $q_{i t} \leq \lambda_{1}$} \\
\hline Physical Capital per Worker & $\begin{array}{l}0.553 \\
(38.2)\end{array}$ & $\begin{array}{l}0.451 \\
(33.9)\end{array}$ & $\begin{array}{l}0.401 \\
(24.8)\end{array}$ & $\begin{array}{l}0.575 \\
(47.7)\end{array}$ \\
\hline Human Capital per Worker & $\begin{array}{l}0.085 \\
(4.56)\end{array}$ & $\begin{array}{l}0.177 \\
(13.7)\end{array}$ & $\begin{array}{l}0.139 \\
(7.27)\end{array}$ & $\begin{array}{c}0.422 \\
(19.3)\end{array}$ \\
\hline Infrastructure per Worker & $\begin{array}{l}0.902 \\
(4.41)\end{array}$ & $\begin{array}{c}0.030 \\
(2.98)\end{array}$ & $\begin{array}{l}0.137 \\
(8.26)\end{array}$ & $\begin{array}{c}0.023 \\
(1.17)\end{array}$ \\
\hline \multicolumn{5}{|l|}{ Regime 2: $\lambda_{1}<q_{i t} \leq \lambda_{2}$} \\
\hline Physical Capital per Worker & $\begin{array}{c}0.580 \\
(41.5)\end{array}$ & $\begin{array}{c}0.526 \\
(40.8)\end{array}$ & $\begin{array}{c}0.455 \\
(25.9)\end{array}$ & $\begin{array}{l}0.641 \\
(5.3 .6)\end{array}$ \\
\hline Human Capital per Worker & $\begin{array}{c}0.084 \\
(5.74)\end{array}$ & $\begin{array}{c}-0.033 \\
(-1.78)\end{array}$ & $\begin{array}{c}-0.046 \\
(-2.13)\end{array}$ & $\begin{array}{l}0.145 \\
(5.63)\end{array}$ \\
\hline Infrastructure per Worker & $\begin{array}{c}0.118 \\
(11.3)\end{array}$ & $\begin{array}{l}0.083 \\
(7.55)\end{array}$ & $\begin{array}{c}0.141 \\
(9.91)\end{array}$ & $\begin{array}{c}0.041 \\
(2.63)\end{array}$ \\
\hline \multicolumn{5}{|l|}{ Regime 3: $q_{i t}>\lambda_{3}$} \\
\hline Physical Capital per Worker & $\begin{array}{c}0.624 \\
(40.7)\end{array}$ & $\begin{array}{c}0.556 \\
(44.6)\end{array}$ & $\begin{array}{l}0.492 \\
(26.08)\end{array}$ & $\begin{array}{c}0.686 \\
(55.6)\end{array}$ \\
\hline Human Capital per Worker & $\begin{array}{l}-0.072 \\
(-2.976)\end{array}$ & $\begin{array}{c}-0.096 \\
(-4.13)\end{array}$ & $\begin{array}{c}-0.154 \\
(-5.38)\end{array}$ & $\begin{array}{l}-0.029 \\
(-1.37)\end{array}$ \\
\hline Infrastructure per Worker & $\begin{array}{c}0.047 \\
(3.26)\end{array}$ & $\begin{array}{c}0.091 \\
(8.10)\end{array}$ & $\begin{array}{c}0.130 \\
(9.21)\end{array}$ & $\begin{array}{c}0.047 \\
(3.54)\end{array}$ \\
\hline \multicolumn{5}{|l|}{ Threshold Estimates } \\
\hline First Threshold $\widehat{\lambda}_{1}$ & 7.838 & 8.310 & 8.289 & 8.374 \\
\hline 95\% Confidence Interval & {$[7.79,7.83]$} & {$[8.25,8.33]$} & {$[8.28,8.33]$} & {$[8.37,8.37]$} \\
\hline Second Threshold $\widehat{\lambda}_{2}$ & 9.222 & 9.234 & 9.234 & 9.076 \\
\hline 95\% Confidence Interval & {$[9.20,9.23]$} & {$[9.20,9.29]$} & {$[9.20,9.33]$} & {$[8.99,9.16]$} \\
\hline
\end{tabular}

Notes: The t-statistics in parenthesis are computed with an estimator of the covariance matrix which allows for heteroskedasticity. The confidence interval for the threshold parameters corresponds to the no rejection region of confidence level $95 \%$ associated to the likelihood ratio statistic for test on the values of the threshold parameters (see Hansen, 1999). This confidence interval can be not symetric. 